\title{
Preoperative CA-125 Value as a Predictive Factor for Postoperative Outcome in First Relapse of Platinum-sensitive Serous Ovarian Cancer
}

\author{
ASYA PARASHKEVOVA ${ }^{1}$, JALID SEHOULI ${ }^{2}$, ROLF RICHTER ${ }^{2}$, DESISLAVA DIMITROVA ${ }^{2}$, \\ ELENA IOANA BRAICU ${ }^{1,2}$ and MUSTAFA ZELAL MUALLEM ${ }^{2}$ \\ ${ }^{1}$ Ovarian Cancer Tumor Bank, and ${ }^{2}$ Department of Gynecology, \\ Virchow Campus Clinic, Charité Medical University, Berlin, Germany
}

\begin{abstract}
Aim: The purpose of the study was to evaluate whether preoperative cancer antigen 125 (CA-125) levels predict outcome of secondary cytoreductive surgery (SCS) in patients with serous recurrent ovarian cancer and whether this could be used as a prognostic factor for progression-free (PFS) and overall (OS) survival. Patients and Methods: A cohort of 111 patients with first recurrence of platinumsensitive serous ovarian cancer, who had undergone SCS at the Department of Gynecology and Oncological Surgery, Charité, Campus Virchow Clinic was analyzed in correlation with the preoperative CA-125 value. Results: The median preoperative CA-125 level was $164 \mathrm{U} / \mathrm{ml}$. Complete tumor resection was achieved in $58.6 \%$ of the patients. PFS and OS for patients with preoperative CA-125 of less than $164.5 \mathrm{U} / \mathrm{ml}$ was significantly better than those with preoperative $C A-125 \geq 164.5 \mathrm{U} / \mathrm{ml}$ ( $p=0.025$ and $p<0.001$, respectively). Conclusion: Preoperative CA-125 is not a statistically significant predictive factor for complete tumor resection after SCS. Preoperative CA-125 $<164.5 \mathrm{U} / \mathrm{ml}$ can predict significantly better PFS and OS for patients with first recurrence of platinum-sensitive ovarian cancer.
\end{abstract}

Epithelial ovarian cancer (EOC) is characterized by an aggressive course and high probability of disease recurrence. Due to lack of early symptoms, EOC is diagnosed mostly at an already advanced stage (1). In recent years, progressionfree (PFS) and overall (OS) survival have been extended due

Correspondence to: Dr. med. Dr. (syr.) Mustafa Zelal Muallem, Charité University Medicine Berlin, Campus Virchow-Klinikum, Augustenburger Platz 1, 13353 Berlin, Germany. Tel: +49 30450664373, Fax: +49 30450564900, e-mail: MustafaZelal.Muallem@charite.de

Key Words: Ovarian cancer, CA-125, secondary cytoreductive surgery, complete tumor resection. to improved surgical skills of gynecological oncologists, better understanding of tumor biology, and implementation of new chemotherapeutic agents (2-7).

The majority of patients with EOC experience relapse even after successful therapy (8-10). The first recurrence is treated with surgery, followed by second-line chemotherapy or with chemotherapy alone (10).

Some studies attempted to define criteria for predicting surgical outcome. The Descriptive Evaluation of Preoperative Selection Criteria for Operability in Recurrent Ovarian Cancer (DESKTOP OVAR) I trial in patients with recurrent ovarian cancer was performed to test the hypothesis that certain criteria could be used for selecting patients who might benefit from surgery in recurrent ovarian cancer (ROC) (11). After retrospective analysis of 267 patients with ROC, the study described the following statistically significant results: patients with complete tumor resection (CTR) had significantly longer survival compared with those who underwent surgery leaving any postoperative residuals; favorable variables associated with complete resection were performance status 0 , International Federation of Gynecology and Obstetrics (FIGO) stage I/II, no tumor present after primary surgery, and absence of ascites. The DESKTOP OVAR II trial confirmed the study hypothesis and introduced the Arbeitsgemeinschaft Gynäkologische Onkologie (AGO) score: 1: complete resection at first surgery, 2: good performance status, 3: absence of ascites, as a predictive score for successful surgery. The study included 516 patients with first or second relapse of serous ovarian cancer. In total, $51 \%$ of these patients were classified as score-positive patients (when all three criteria were met). CTR was achieved In $76 \%$ of AGO score-positive patients. This score was the first prospectively validated instrument to predict positive surgical outcome in ROC (2).

The prospective DESKTOP III trial study showed that patients with platinum-sensitive first relapse of ovarian cancer and positive AGO score benefited from secondary cytoreductive surgery (SCS); these patients had a clinically 
meaningful increased PFS and time to start of first subsequent therapy, with acceptable treatment burden. This gives physicians a valuable option in the decision regarding surgical therapy for patients with first relapse in EOC (12).

One established clinical parameter of ovarian cancer is the cancer antigen 125 (CA-125). It promotes cancer cell proliferation and inhibits anticancer immune responses (1315). CA-125 is implemented in the diagnosis of primary EOC and ROC. Moore et al. described the Risk of Ovarian Malignancy Algorithm (ROMA Index), CA-125/HE4 Index, which helped to detect EOC depending on pre/postmenopausal status of the patients with high sensitivity and moderate specificity for both pre- and postmenopausal women (16).

The main objective of our study was to evaluate if the preoperatively measured CA-125 level predicted the outcome of SCS in patients with serous ROC and whether it could be used as prognostic factor for PFS and OS.

\section{Materials and Methods}

A total of 111 patients with first recurrence of platinum-sensitive serous ovarian cancer were included in this retrospective study. The patients were recruited from the Ovarian Cancer Tumor Bank (www.toc-network.de). This database, essentially, a prospective documentation tool, includes clinical data, disease history, tumor spread, presence of ascites, and presence and location of residual tumor mass intra-operatively obtained through an interview with the surgeon immediately postoperatively. All participants gave their inform consent. The study was approved from Charité Medical University local Ethics Committee (EK207/2003). The clinical data were extracted from patient's records.

The optimal surgical outcome after SCS was defined as no macroscopic tumor residual (R0) or CTR.

All patients included in the study had platinum- sensitive disease (recurrence after more than 6 months from the end of platinumbased chemotherapy) and received a platinum-based chemotherapy 6-8 weeks after SCS. Cancer staging in the study was based on the FIGO classification prior to 2014 to match the database (17). The CA-125 level was measured preoperative in $\mathrm{U} / \mathrm{ml}$ in blood serum using Elecsys ${ }^{\circledR}$ CA-125 II (Roche diagnostics, Basel, Switzerland).

Patients with platinum-resistant recurrence were excluded from the analysis, as were patients with histology other than serous papillary, patients without preoperative CA-125 evaluation and those who had been treated for second malignancy in the 5 years before first diagnosis of EOC.

At the end of treatment, patients were regularly evaluated for evidence of new recurrence by clinical examination, transvaginal and transabdominal sonography, and CA-125 (if the preoperative value was elevated). A computerized tomography (CT)/ magnetic resonance imaging (MRI) examination was performed if the above examinations revealed pathological findings. No treatment decisions were taken based only on raised CA-125 level.

The statistical analysis was performed at Charité Medical University Berlin using IBM SPSS Statistics 22.0 (IBM Corp., Armonk, NY, USA). Descriptive statistic tests were used to characterize the patient cohort and Kolmogorov-Simirnov test to characterize the distribution of preoperative CA-125 levels.
Table I. Characteristics of 111 patients with first platinum-sensitive relapse of serous epithelial ovarian cancer underwent secondary cytoreductive surgery (SCS) in Charité Medical University, Berlin, Germany.

\begin{tabular}{lc}
\hline Characteristic & Value \\
\hline Age at first relapse, years & \\
$\quad$ Median (range) & $55(28-85)$ \\
CA-125, U/ml & \\
$\quad$ Median (range) & $164(5-29000)$ \\
FIGO classification at first diagnosis, n (\%) & \\
II & $4(3.6 \%)$ \\
III & $89(80.2 \%)$ \\
IV & $16(14.4 \%)$ \\
Grading, n (\%) & \\
Low & $31(27.9 \%)$ \\
High & $78(70.3 \%)$ \\
Ascites, n (\%) & \\
None & $64(57.7 \%)$ \\
$<500$ ml & $37(33.3 \%)$ \\
$\geq 500$ ml & $10(9 \%)$ \\
Residual tumor, n (\%) & \\
R0 & $65(58.6 \%)$ \\
R1 & $46(41.4 \%)$ \\
Lymph node status, n (\%) & \\
N0 & $16(14.4 \%)$ \\
N1 & $51(45.9 \%)$ \\
Nx & $44(39.6 \%)$ \\
\hline
\end{tabular}

CA-125: Cancer Antigen-125 ( $<35 \mathrm{U} / \mathrm{ml})$; FIGO: International Federation of Gynecology and Obstetrics (17).

With receiving operating characteristics analysis, sensitivity and specificity were calculated to define the optimal cut-off value of preoperative CA-125 for predicting CTR.

The correlation between preoperative CA-125 levels and clinical factors such as age, ascites, grading, FIGO stage and CTR was investigated using non-parametric univariate tests such as Kendall's Tau-b, Spearman's Rho, Wilcoxon-Mann-Whitney test and Kruskal-Wallis test and again with a multivariate analysis.

Median and 95\% confidence intervals (95\% CI) for PFS and OS were estimated according to the Kaplan-Meier method. PFS was defined as the length of time between the end of the last chemotherapy cycle to the occurrence of the second relapse. OS was determined as the length of time between SCS for the first relapse and the date of death or end of follow-up. Statistical significance was defined by $p<0.05$ and two-sided tests were applied.

\section{Results}

A total of 111 patients in an ROC cohort were investigated and CA-125 measured before SCS in all patients. The median age of patients at the time of SCS was 55 years. The patients characteristics are presented in Table I. Overall, 96.2\% of patients were diagnosed with advanced stage at the time of first diagnosis of EOC. Only $3.6 \%$ of the patients in this cohort had an early stage (FIGO II) at the time of first diagnosis. 

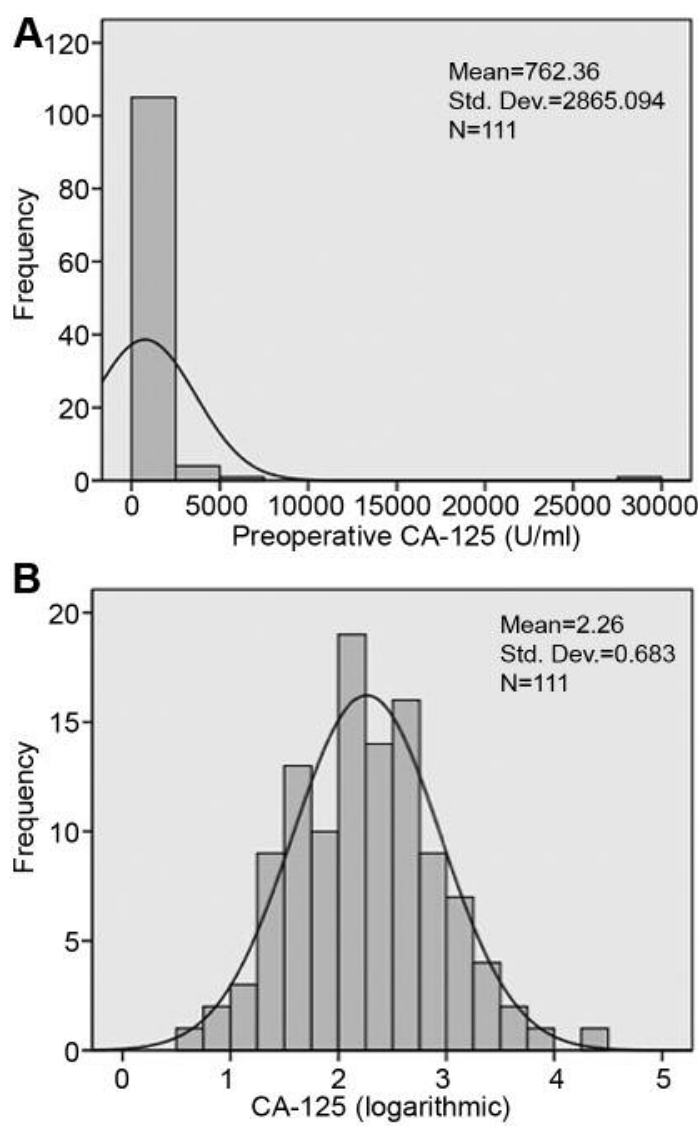

Figure 1. Distribution of preoperative cancer antigen (CA)-125 in our collective. A: Kolmogorov-Smirnov test presents a non-normal distribution. B: Values were approximately normal (Gaussian) distributed after logarithmic conversion.

Most patients with ROC had no ascites at the time of SCS (57.7\%), whereas $9 \%$ had $500 \mathrm{ml}$ ascites or more. Of all cases with ROC, $67.4 \%$ underwent lymph node dissection in the frame of their SCS and the final histological study showed affected lymph nodes in $45.9 \%$ of the total cohort (76.1\% of patients with lymph node dissection as a part of SCS). CTR was achieved in $58.6 \%$ of the patients; in the remaining patients, different volumes of residual tumor could not be resected.

The median preoperative CA-125 level was $164 \mathrm{U} / \mathrm{ml}$ and the mean value was $762.36 \mathrm{U} / \mathrm{ml}(95 \% \mathrm{CI}=223.43-1,301.28$ $\mathrm{U} / \mathrm{ml}$ ). The mean follow-up period was 26.4 months. Kolmogorov-Smirnov test showed the preoperative CA-125 levels were not normally distributed in this cohort (Figure 1A). Logarithmic conversion of CA-125 values led to normalization (Gaussian) of their distribution (Figure 1B).

Correlation between preoperative CA-125 levels and the outcomes of SCS. Using receiver operating characteristics

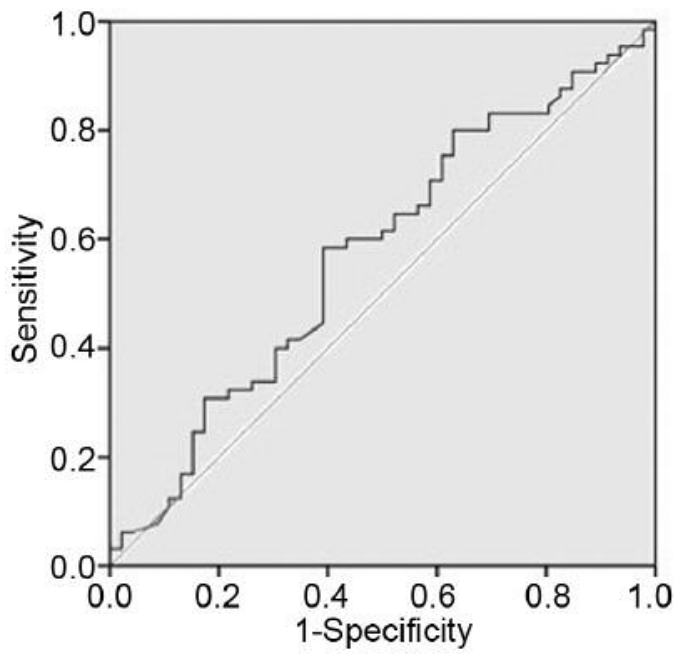

Figure 2. Receiver operating characteristic curve analysis. Representation of area under the curve $=0.572(p=0.195)$.

analysis, there was no prognostic power of preoperative CA125 to predict CTR, which is the most important prognostic factor of ROC after SCS. Since, the area under curve (AUC) was small for the prognostic value of preoperative CA-125; it was prudent to set a cut-off value of preoperative CA-125 which would predict the CTR. Therefore the estimated optimal preoperative CA-125 cut-off value in our study was $164.5 \mathrm{U} / \mathrm{ml}$, with highest sum of sensitivity $(58.5 \%)$ and specificity $(60.9 \%)$, allowing prediction of the chance for CTR as $58.5 \%$ for patients who had CA-125 less than 164.5 $\mathrm{U} / \mathrm{ml}$ before SCS, with corresponding AUC of 0.572 $(p=0.195)$, which means the distribution of false-positive and true-positive results could be accidental (Figure 2).

Correlation between preoperative CA-125 levels and PFS or $O S$. For the survival analyses, the cut-off value of 164.5 $\mathrm{U} / \mathrm{ml}$ was used to compare the relationship of preoperative CA-125 level with PFS and OS using Kaplan-Meier curves. PFS and OS were significantly better for patients with preoperative CA-125 of less than $164.5 \mathrm{U} / \mathrm{ml}$ than those with preoperative CA-125 $\geq 164.5 \mathrm{U} / \mathrm{ml}$ ( $p=0.025$ and $p<0.001$, respectively; Figure 3). Median PFS was 20 (95\% CI=16.723.3) and 13 (95\% CI=10.1-15.8) months, and median OS was $46.3(95 \% \mathrm{CI}=4-68.5)$ and 25 (95\% CI=18.4-31.6) months after SCS with and without CTR, respectively.

Correlation between preoperative CA-125 values and the important clinical prognostic factors. Univariate analysis of the conventional clinical prognostic factors for ROC and its correlation to preoperative CA-125 showed higher values of preoperative CA-125 in patients with ascites compared to those without ascites, and in patients with advanced-stage 

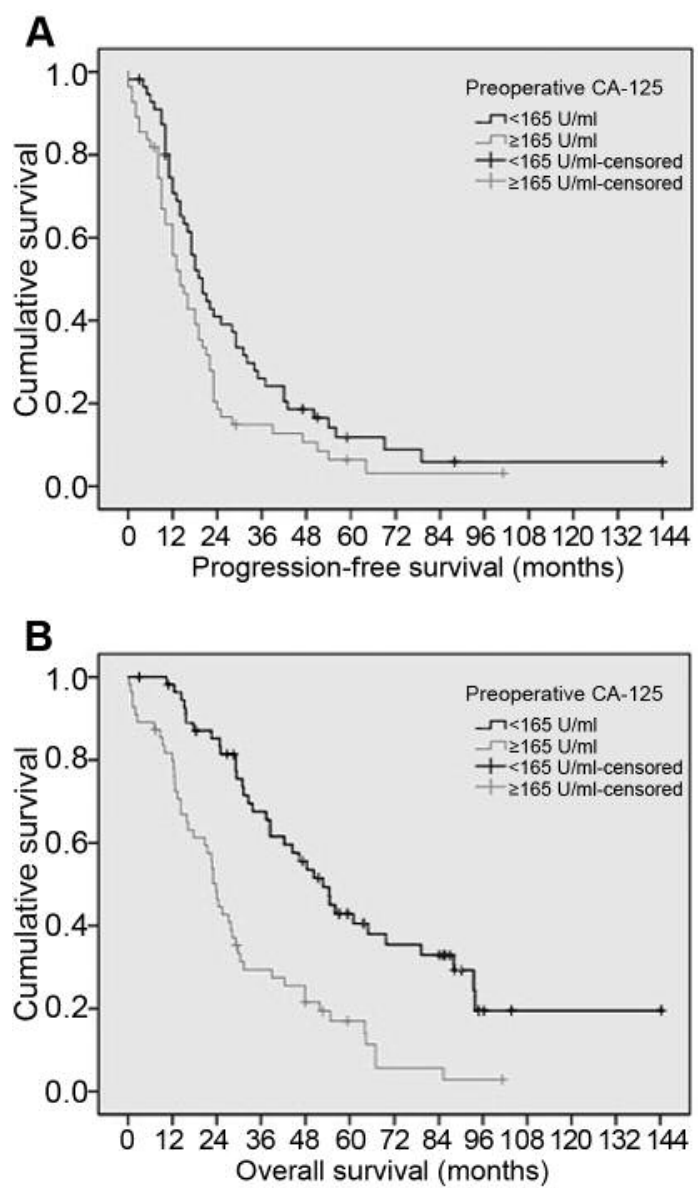

Figure 3. Progression-free $(A)$ and overall survival $(B)$ in the two groups of patients with recurrent serous ovarian cancer according to preoperative cancer antigen (CA)-125 value.

EOC at first diagnosis (FIGO III and IV) compared to patients with early-stage of EOC (FIGO I or II). These two correlations were weak to moderate. Wilcoxon-Mann-Whitney test indicated higher preoperative CA-125 values in patients with $\geq 500 \mathrm{ml}$ ascites compared to those with $<500 \mathrm{ml}(p=0.033)$, and those without ascites $(p=0.027)$.

The multivariate analysis reported a higher risk for residual tumor in patients with diffuse peritoneal cancer compared to those without diffuse peritoneal dissemination $(p<0.001)$.

\section{Discussion}

The role of SCS in ROC has not been defined by level-1 evidence. Such evidence may be provided by the final results of DESKTOP III trial. Until then, SCS should at least be considered as a valuable option in patients with a positive AGO score (12). The AGO score, developed within a retrospective analysis and validated in a prospective independent cohort, has gained attention in treatment of patients with ROC. Harter et al. concluded that the positive predictive value of the AGO score in patients with first relapse was $76 \%$ (2); the negative predictive value was only $38 \%$ and specificity was low at $53 \%$.

The AGO score does not include CA-125 as one of its criteria for a positive score, therefore in this study, we tried to test the predictive value of preoperative CA-125 for postoperative outcome in SCS in term of CTR, PFS and OS independently from the AGO-Score; and we aimed to evaluate the correlation between preoperative CA-125 levels and important clinical prognostic factors.

In this study, a cut-off value of preoperative CA- 125 with sub-optimal prognostic power was set at $164.5 \mathrm{U} / \mathrm{ml}$. In the study of Mahner et al., a CTR was achieved in 33\% of the patients (18). This rate was higher in our study at $58.6 \%$. Muallem et al. from our Institute reported a CTR rate of $61 \%$ after SCS in all patients with ROC (19). This rate was increased to $67 \%$ by including only patients with a positive AGO-Score, which is identical to the CTR rate reported in the SCS arm of DESKTOP III trail for patients with a positive AGO-score. The rate of CTR registered by Harter $e t$ al. was $49.8 \%$ (11). In other studies, the CTR rate ranged between $9 \%$ and $82 \%$ (20-38). This difference could be due to the procedures having been performed in a tertiary center by highly experienced surgeons in our study.

Mahner et al. also investigated the prognostic value of CA-125 in the management of patients with ROC selected for SCS and included 36 patients in their study (18). They reported that preoperative $\mathrm{CA}-125$ was elevated $(>35 \mathrm{U} / \mathrm{ml})$ at the time of ROC in 30 out of 36 patients $(81 \%)$, with a median of $212 \mathrm{U} / \mathrm{ml}$ in comparison with our median preoperative CA-125 of $164 \mathrm{U} / \mathrm{ml}$. They concluded that preoperative CA-125 had no prognostic relevance. The only independent prognostic factors of improved survival were the progression-free interval before SCS $(p=0.047)$ and minimal residual disease after SCS $(p=0.024)$. Harter et al. reviewed prognostic factors for CTR after primary cytoreductive surgery and SCS for EOC. They were unable to find sufficient predictive markers (including preoperative CA125 ) for CTR in both groups (39). In our previous study on preoperative CA-125 value as a predictive factor for postoperative outcome in primary serous ovarian cancer, we concluded that preoperative CA-125 was a statistically significant predictive factor for CTR after primary cytoreductive surgery (40). However, preoperative CA-125 cannot predict PFS nor OS for patients with primary serous ovarian cancer. In contrast to this conclusion, the current study about ROC showed the preoperative CA-125 had no prognostic significance and was unable to predict the CTR. On the other hand, PFS and OS was better for patients with preoperative CA-125 of less than $164.5 \mathrm{U} / \mathrm{ml}(p=0.025$ and $p<0.001$, respectively). 
Limiting factors of this study were its retrospective design, and that the FIGO classifications provided were defined according to the old classification system. Nevertheless, our study has convincing advantages. The study cohort was restricted to patients with serous ROC, therefore only patients with preoperative CA-125 values, assumed to reflect the peritoneal dissemination of cancer, were included. In addition, the rather high number of patients in this collective, the high rate of CTR and the long median follow-up period add value to our findings.

In conclusion, preoperative CA-125 is a poor, not statistically significant predictive factor for CTR after SCS. Preoperative CA-125 <164.5 U/ml can predict significantly better PFS and OS for patients with first relapse of platinumsensitive EOC.

\section{Conflicts of Interest}

There exists no financial or personal conflict of interest by any of the Authors to declare.

\section{References}

1 Heintz AP, Odicino F, Maisonneuve P, Quinn MA, Benedet JL, Creasman WT, Ngan HY, Pecorelli S and Beller U: Carcinoma of ovary. FIGO 26th Annual Report on the Results of Treatment in Gynecological Cancer. Int J Gynaecol Obstet 95(1): 161-192, 2006.

2 Harter P1, Sehouli J, Reuss A, Hasenburg A, Scambia G, Cibula D, Mahner S, Vergote I, Reinthaller A, Burges A, Hanker L, Pölcher M, Kurzeder C, Canzler U, Petry KU, Obermair A, Petru E, Schmalfeldt B, Lorusso D and du Bois A: Prospective validation study of a predictive score for operability of recurrent ovarian cancer: the Multicenter Intergroup Study DESKTOP II: A project of the AGO Kommission OVAR, AGO Study Group, NOGGO, AGO-Austria, and MITO: Int J Gynecol Cancer 21(2): 289-295, 2011.

3 Bristow RE, Tomacruz RS, Armstrong DK, Trimble EL and Montz FJ: Survival effect of maximal cytoreductive surgery for advanced ovarian carcinoma during the platinum era: a metaanalysis. J Clin Oncol 20(5): 1248-1259, 2002.

4 Panici PB, Maggioni A, Hacker N, Landoni F, Ackermann S, Campagnutta E, Tamussino K, Winter R, Pellegrino A, Greggi S, Angioli R, Manci N, Scambia G, Dell'Anna T, Fossati R, Floriani I, Rossi RS, Grassi R, Favalli G, Raspagliesi F, Giannarelli D, Martella L and Mangioni C: Systematic aortic and pelvic lymphadenectomy versus resection of bulky nodes only in optimally debulked advanced ovarian cancer: a randomized clinical trial. J Natl Cancer Inst 97(8): 560-566, 2005.

5 Gagliardi AR, Fung MF, Langer B, Stern H and Brown AD: Development of ovarian cancer surgery quality indicators using a modified Delphi approach. Gynecol Oncol 97(2): 446-456, 2005.

6 Clarke - Pearson DL: Clinical practice. Screening for ovarian cancer. N Engl J Med 361(2): 170-177, 2009.

7 Meyer T and Rustin GJ: Role of tumor markers in monitoring epithelial ovarian cancer. Br J Cancer 82(9): 1535-1538, 2000.
8 Ozols RF, Bundy BN, Greer BE Fowler JM, Clarke-Pearson D, Burger RA, Mannel RS, DeGeest K, Hartenbach EM, Baergen $\mathrm{R}$ and Gynecologic Oncology Group: Phase III trial of carboplatin and paclitaxel compared with cisplatin and paclitaxel in patients with optimally resected stage III ovarian cancer: a Gynecologic Oncology Group study. J Clin Oncol 21(17): 31943200, 2003.

9 du Bois A1, Lück HJ, Meier W, Adams HP, Möbus V, Costa S, Bauknecht T, Richter B, Warm M, Schröder W, Olbricht S, Nitz U, Jackisch C, Emons G, Wagner U, Kuhn W and Pfisterer J; Arbeitsgemeinschaft Gynäkologische Onkologie Ovarian Cancer Study Group: A randomized clinicaltrial of cisplatin/paclitaxel versus carboplatin/paclitaxel as first-line treatment of ovarian cancer. J Natl Cancer Inst 95(17): 1320-1329, 2003.

10 Pignata S, Cecere SC, du Bois A, Harter P and Heitz F: Treatment of recurrent ovarian cancer. Ann Oncol 28(8): viii51viii56, 2017.

11 Harter P, du Bois A, Hahmann M, Hasenburg A, Burges A, Loibl S, Gropp M, Huober J, Fink D, Schröder W, Muenstedt K, Schmalfeldt B, Emons G, Pfisterer J, Wollschlaeger K, Meerpohl HG, Breitbach GP, Tanner B and Sehouli J: Surgery in recurrent ovarian cancer: The Arbeitsgemeinschaft Gynaekologische Onkologie (AGO) DESKTOP OVAR Trial. Ann Surg Oncol 12(13): 1702-1710, 2006.

12 du Bois A, Vergote I, Ferron G, Reuss A, Meier W, Greggi S, Jensen PT, Selle F, Guyon F, Pomel C, Lecuru F, Zang R, AvallLundqvist E, Kim JW, Ponce J, Raspagliesi F, Ghaem-Maghami S, Reinthaller A, Harter P and Sehouli J: Randomized controlled phase III study evaluating the impact of secondary cytoreductive surgery in recurrent ovarian cancer: AGO DESKTOP III/ENGOT ov20. J Clin Oncol 35(15): 5501, 2017.

13 Bast RC Jr. and Spriggs DR: More than a biomarker: CA-125 may contribute to ovarian cancer pathogenesis. Gynecol Oncol 121(3): 429-430, 2011.

14 Comamala M, Pinard M, Theriault C, Matte I, Albert A, Boivin M, Beaudin J, Piche A and Rancourt C: Downregulation of cell surface CA-125/MUC16 induces epithelial to mesenchymal transition and restores EGFR signalling in NIH:OVCAR3 ovarian carcinoma cells. Br J Cancer 104(6): 989-999, 2011.

15 Kaesemann H, Caffier H, Hoffmann FJ, Crombach G, Würz H, Kreienberg R, Möbus V, Schmidt Rode P and Sturm G: Monoklonale Antikörper in Diagnostik und Verlaufskontrolle des Ovarialkarzinoms. CA-125 als Tumormarker. Klin Wschr 109: 1949-54, 1986.

16 Moore RG, Miller MC, Disilvestro P, Landrum LM, Gajewski W, Ball JJ and Skates SJ: Evaluation of the diagnostic accuracy of the risk of ovarian malignancy algorithm in women with a pelvic mass. Obstet Gynecol 118(2): 280-288, 2011.

17 FIGO Cancer Committee: Staging announcement. Gynecol Oncol 25: 383-385, 1986

18 Mahner S, Woelber L, Jung S, Eulenburg CZ, Ihnen M, Schwarz J, Sehouli J and Jaenicke F: Prognostic significance of CA-125 in the management of patients with recurrent epithelial ovarian carcinoma selected for secondary cytoreduction. Anticancer Res 29(7): 2817-2821, 2009.

19 Muallem MZ, Gasimli K, Richter R, Almuheimid J, Nasser S, Braicu I and Sehouli J: AGO Score as a predictor of surgical outcome at secondary cytoreduction in patients with ovarian cancer. Anticancer Res 35(6): 3423-3429, 2015. 
20 Eisenkop SM, Friedman RL and Spirtos NM: The role of secondary cytoreductive surgery in the treatment of patients with recurrent epithelial ovarian cancer. Cancer 88(1): 144-153, 2000.

21 Cormio G, di Vagno G, Cazzolla A, Bettocchi S, di Gesu G, Loverro G and Selvaggi L: Surgical treatment of recurrent ovarian cancer: report of 21 cases and a review of the literature. Eur J Obstet Gynecol Reprod Biology 86(2): 185-188, 1999.

22 Gadducci A, Iacconi P, Cosio S, Fanucchi A, Cristofani R and Riccardo Genazzani A: Complete salvage surgical cytoreduction improves further survival of patients with late recurrent ovarian cancer. Gynecol Oncol 79(3): 344-349, 2000.

23 Gronlund B, Lundvall L, Christensen IJ, Knudsen JB and Høgdall C: Surgical cytoreduction in recurrent ovarian carcinoma in patients with complete response to paclitaxelplatinum. Eur J Surgical Oncology 31(1): 67-73, 2005.

24 Gungor M, Ortac F, Arvas M, Kosebay D, Sonmezer M and Kose K: The role of secondary cytoreductive surgery for recurrent ovarian cancer. Gynecol Oncol 97(1): 74-79, 2005.

25 Harter P, Breitbach GP, Tanner B, Sehouli J, Heilmann V, Lueck HJ, Kuhn W, Wimberger P, Ortmann $\mathrm{O}$ and du Bois A: Preoperative selection criteria for operability in recurrent ovarian cancer. A study of the AGO Organkommission Ovar and the AGO Ovarian Cancer Study Group (AGO-OVAR). Proc Am Soc Clin Oncol 23(Suppl 1): Abstr 5004, 2005.

26 Jänicke F, Hölscher M, Kuhn W, von Hugo R, Pache L, Siewert JR and Graeff $\mathrm{H}$ : Radical surgery procedure improves survival time in patients with recurrent ovarian cancer. Cancer $70(8)$ : 2129-2136, 1992.

27 Kuhn W, Schmalfeldt B, Pache L, Späthe K, Ulm K, Renziehausen K, Nöschel H, Canzler E, Richter B, Kroner M, Tilch G, Janicke F and Graeff H: Disease-adapted relapse therapy for ovarian cancer: results of a prospective study. Int J Oncol 13(1): 57-63, 1998.

28 Leitao MM, Kardos S, Barakat RR and Chi DS: Tertiary cytoreduction in patients with recurrent ovarian cancer. Gynecol Oncol 95: 181-185, 2004.

29 Loehr A, Harter P, Traut A, Gnauert K and du Bois A: Cytoreductive surgery in recurrent ovarian cancer. J Cancer Res Clin Oncol 130(1): 122, 2004.

30 Morris M, Gershenson DM, Wharton JT, Copeland LJ, Edwards $\mathrm{CL}$ and Stringer CA: Secondary cytoreductive surgery for recurrent epithelial ovarian cancer. Gynecol Oncol 34(3): 334-338, 1989.
31 Munkarah A, Levenback C, Wolf JK, Bodurka-Bevers D, Tortolero-Luna G, Morris RT and Gershenson DM: Secondary cytoreductive surgery for localized intra-abdominal recurrences in epithelial ovarian cancer. Gynecol Oncol 81(2): 237-241, 2001.

32 Onda T, Yoshikawa H, Yasugi T, Yamada M, Matsumoto K and Taketani Y: Secondary cytoreductive surgery for recurrent epithelial ovarian carcinoma: proposal for patients selection. $\mathrm{Br}$ J Cancer 92(6): 1026-1032, 2005.

33 Pecorelli SP, Sartori E and Santin A: Follow-up after primary therapy: management of the symptomatic patient-surgery. Gynecol Onncol 55(3): 138-142, 1994.

34 Scarabelli C, Gallo A and Carbone A: Secondary cytoreductive surgery for patients with recurrent epithelial ovarian carcinoma. Gynecol Oncol 83(2): 504-512, 2001.

35 Tay EH, Grant PT, Gebski V and Hacker NF: Secondary cytoreductive surgery for recurrent epithelial ovarian cancer. Obstet Gynecol 99(6): 1008-1013, 2002.

36 Vaccarello L, Rubin SC, Vlamis V, Wong G, Jones WB, Lewis JL and Hoskins WJ: Cytoreductive surgery in ovarian carcinoma patients with a documented previously complete surgical response. Gynecol Oncol 57(1): 61-65, 1995.

37 Zang RY, Zhang ZY, Li ZT, Chen J, Tang MQ, Liu Q and Cai SM: Effect of cytoreductive surgery on survival of patients with recurrent epithelial ovarian cancer. J Surg Oncol 75(1): 24-30, 2000.

38 Zang RY, Li ZT, Tang J, Cheng X, Cai SM, Zhang ZY and Teng $\mathrm{NN}$ : Secondary cytoreductive surgery for patients with relapsed epithelial ovarian carcinoma: Who benefits? Cancer 100(6): 1152-1161, 2004.

39 Harter P, Hilpert F, Mahner S, Kommoss S, Heitz F, Pfisterer J and du Bois A: Prognostic factors for complete debulking in first-and second-line ovarian cancer. Int J Gynecol Cancer 19(2): 14-17, 2009.

40 Muallem MZ, Parashkevova A, Almuheimid J, Richter R, Diab Y, Braicu I and Sehouli J: Preoperative CA-125 values as a predictive factor for the postoperative outcome in primary serous ovarian cancer. Anticancer Res 37(6): 3157-3161, 2017.

Received March 16, 2018

Revised April 18, 2018

Accepted April 30, 2018 